\title{
Tea consumption and the risk of biliary tract cancer: a systematic review and dose-response meta-analysis of observational studies
}

\author{
Jianping Xiong ${ }^{1, *}$, Jianzhen Lin ${ }^{1, *}$, Anqiang Wang ${ }^{1, *}$, Yaqin Wang ${ }^{2}$, Ying Zheng ${ }^{3}$, \\ Xinting Sang ${ }^{1}$, Yiyao $\mathrm{Xu}^{1}$, Xin Lu ${ }^{1}$, Haitao Zhao ${ }^{1}$ \\ ${ }^{1}$ Department of Liver Surgery, Peking Union Medical College Hospital, Chinese Academy of Medical Sciences and Peking \\ Union Medical College, Beijing, China \\ ${ }^{2}$ Department of Interventional Radiology, The First Affiliated Hospital of China Medical University, Shenyang, China \\ ${ }^{3}$ State Key Laboratory of Quality Research in Chinese Medicine, Institute of Chinese Medical Science, University of Macau, \\ Macau SAR, China \\ *These authors contributed equally to this work
}

Correspondence to: Yiyao Xu, email: xuyiyao@hotmail.com

Xin Lu, email: luxinln@163.com

Haitao Zhao, email: zhaoht@pumch.cn

Keywords: tea, biliary tract cancer, cholangiocarcinoma, bile duct cancer

Received: January 09, 2017 Accepted: March 29, $2017 \quad$ Published: April 08, 2017

Copyright: Jianping Xiong et al. This is an open-access article distributed under the terms of the Creative Commons Attribution License 3.0 (CC BY 3.0), which permits unrestricted use, distribution, and reproduction in any medium, provided the original author and source are credited.

\section{ABSTRACT}

Recent studies have shown that tea consumption is associated with the reduced incidence of some types of cancer, possibly including biliary tract cancer. However, the epidemiological evidences for the association with risk of biliary tract cancer are contradictory. Thus, we performed meta-analysis of published observational studies to assess the association between tea consumption and risk of biliary tract cancer. Relevant studies were identified by searching PubMed, EMBASE, and ISI Web of Science published before October 2016. The Newcastle-Ottawa Scale was used to evaluate the quality of included studies, and publication bias was evaluated using funnel plots, and Begg's and Egger's tests. This meta-analysis includes eight studies comprising 18 independent reports. The incidence of biliary tract cancer reduced about 34\% (significantly) for tea intake group in comparison with never intake group (summary odds ratio $[O R]=0.66 ; 95 \%$ confidence interval $[\mathrm{CI}]=0.48-0.85)$. Additionally, an inverse relationship between tea intake and risk of biliary tract cancer was statistically significant in women $(\mathrm{OR}=0.65 ; 95 \% \mathrm{CI}=$ $0.47-0.83)$, but not in men $(O R=0.86 ; 95 \% C I=0.58-1.13)$. Dose- response analysis indicated that the risk of biliary tract cancer decreased by $4 \%$ with each additional cup of tea one day (relative risk $[R R]=0.96,95 \% \mathrm{CI}=0.93-0.98, p=0.001$ ). In summary, tea intake is associated with decreased risk of biliary tract cancer, especially for women.

\section{INTRODUCTION}

Biliary tract cancer, including gallbladder cancer (GC), extra hepatic bile ducts cancer (EXHBDC) and ampulla of Vater cancer (VOA) [1], is relatively rare, highly malignant, and has a high mortality rate. The overall 1-, 3- and 5-year relative survival rates are reportedly $25.0 \%, 9.7 \%$ and $6.8 \%$, respectively, and have barely changed in the past few decades [2]. Although the incidence of biliary tract cancer is relatively low worldwide, the incidence is relatively high in some countries and regions of Latin America and Asia, for example, Japan (4/100 000 women), Chile (16.6/100 000 women),
India (8.5/100 000 women), Korea (5.6/100 000 women), and Shanghai, China (5.2/100 000 women) [3]. About 7500 individuals are diagnosed with biliary tract cancer annually in the USA [4].However, the causes of biliary tract cancer are still not well understood. Only a few risk factors have been identified, including gallstone disease, primary sclerosing cholangitis, and biliary tract infection [5-9]. Some studies have reported other possible risk factors for biliary tract cancer, including parity or age at first birth [10], diabetes [11],obesity [12], smoking [13], medical conditions, and family history of cancer [14]. However, the relationship between diet, especially tea, and biliary tract cancer is not yet well understood. 
Tea is one of the most popular beverages worldwide, especially in Asia. Meantime, it is becoming more and more popular in the West. It is a drink for thousands of years with now growing interests in its additional benefits in health. For example, Studies have indicated that tea intake was associated with the reduced incidence of cardiovascular disease and increased bone density $[15,16]$. In addition, tea is also associated with reduced risk of many types of cancer, including oral, bladder, esophageal, lung, breast, stomach, and liver cancer [1727]. Although many observational studies have reported the relationship between tea and biliary tract cancer [2835], no published studies could confirm the relationship. Therefore, we performed meta-analysis to present the association of them more comprehensive.

\section{RESULTS}

\section{Study selection and study characteristics}

Figure 1 shows the process of selecting studies for the meta-analysis. We obtained 8708 articles through the initial search, 2441 of which were duplicated. We further excluded 6122 studies based on title and abstract review. Finally, we identified eight eligible observational studies for our metaanalysis, including five case-control and three cohort studies.

The main characteristics of the included studies are listed in Supplementary Table 3. Two of them were performed in the USA, two in China, two in Japan, one in Poland, and one in Italy. There were a total of 7968 cases with biliary tract cancer in these studies, including 3802 with GC, 3808 with EXHBDC, and 358 with VOA. The duration of follow-up ranged from 2 to 13 years. The NOS scores for case control studies ranged from 6 to 8 , with three high quality studies and two medium quality studies (Supplementary Table 1). All cohort studies were of high quality studies (Supplementary Table 2).

\section{Overall results}

Overall, we found that tea intake was associated with a reduced incidence of biliary tract cancer (summary OR $=0.66$, $95 \% \mathrm{CI}=0.48-0.85 ; P^{2}=81.1 \%, p=0.001$ ) (Figure 2). The results were similar for tea consumption and GC risk (summary $\mathrm{OR}=0.72,95 \% \mathrm{CI}=0.56-0.88 ; P^{2}=56.1 \%$, $p=0.044$ ) (Table 1). We also found that tea intake was associated with a significantly lower risk of EXHBDC (OR = $0.80,95 \%$ CI $=0.71-0.89 ; P^{2}=0.3 \%, p=0.404$ ) (Table 1 ). However, the inverse relationship between tea intake and the risk of VOA cancer was not statistically significant (OR $\left.=0.78,95 \% \mathrm{CI}=0.49-1.08 ; I^{2}=59.8 \%, p=0.083\right)($ Table 1$)$.

\section{Subgroup and sensitivity analyses}

The results of subgroup analyses are shown in Table 1 . When the analysis was stratified by sex, we found tea was associated with a significantly lower risk of biliary tract cancer in women $(\mathrm{OR}=0.65,95 \% \mathrm{CI}=0.47-0.83$; $\left.\mathrm{I}^{2}=86.7 \%, p=0.001\right)$ rather than in men $(\mathrm{OR}=0.86,95 \%$ $\left.\mathrm{CI}=0.58-1.13 ; \mathrm{I}^{2}=0.6 \%, p=0.650\right)$ (Table 1). According to sensitivity analyses, by excluding studies that were ineligible for dose-response analysis, the relationship between tea intake and biliary tract cancer still remain stable $\left(\mathrm{OR}=0.77,95 \% \mathrm{CI}=0.67-0.88 ; \mathrm{I}^{2}=41.5 \%\right.$, $p=0.114)$ (Table 1).

\section{Dose-response meta-analysis}

Five studies (three case control and two cohort) with a total of 7011 patients with biliary tract cancer were eligible for the assessment of the dose-response relationship between tea intake and the risk of biliary tract cancer. When we used the restricted cubic splines model, we found that the test of a nonlinear relationship between tea intake and biliary tract cancer was rejected $(\mathrm{p}$ for nonlinearity $=0.1902)$. Therefore, we identified a linear relationship with a linear regression model ( $p$ for linearity $=0.0004)$. We found that the risk of biliary tract cancer decreased by $4 \%$ with each additional cup of tea one day $(\mathrm{RR}=0.96,95 \% \mathrm{CI}=0.93-0.98, \mathrm{p}=0.001)($ Figure 3$)$. In addition, when we stratified the dose-response analysis by subtype of cancer, we obtained similar result for $\mathrm{GB}$ cancer ( $\mathrm{p}$ for nonlinearity $=0.1902$; $\mathrm{p}$ for linearity $=0.0004$ ) and EXHBDC ( $\mathrm{p}$ for nonlinearity $=0.6394$; $\mathrm{p}$ for linearity $=0.0064)$. Each additional cup/day of tea was associated with a $4 \%$ decreased risk of GB cancer (RR $=0.96,95 \% \mathrm{CI}=0.93-0.99, p=0.024)$ (Figure 3 ) and $5 \%$ EXHBDC $(\mathrm{RR}=0.95,95 \% \mathrm{CI}=0.92-0.99, p=0.006)$ (Figure 3), respectively. There were too few cases of VOA $(n<3)$ to perform a dose-response analysis.

\section{Publication bias}

Although the number of studies included in the meta-analysis was less than ten, the funnel plots still did not reveal substantial asymmetry. Additionally, Begg's and Egger's tests did not identify substantial publication bias $(p>0.05)$ (Figure 4).

\section{DISCUSSION}

As far as we know, this is the most comprehensive study to explore the relationship between tea and biliary tract cancer. We found that tea intake is associated with a $34 \%$ lower incidence of biliary tract cancer $(\mathrm{OR}=0.66$; $95 \%$ CI $=0.48-0.85)$. Subgroup analysis by type of cancer yielded similar results for risk of $\mathrm{GB}$ cancer $(\mathrm{OR}=0.72$; 95\% CI $=0.56-0.88)$ and EXHBDC $(\mathrm{OR}=0.80,95 \%$ $\left.\mathrm{CI}=0.71-0.89 ; \mathrm{I}^{2}=0.3 \%, p=0.404\right)$, respectively. However, we did not find a statistically significant inverse relationship between tea intake and the risk of $\operatorname{VOA}(\mathrm{OR}=0.78 ; 95 \% \mathrm{CI}=0.49-1.08)$. Additionally, we 
identified a statistically significant inverse relationship between tea intake and the risk of biliary tract cancer in women $(\mathrm{OR}=0.65 ; 95 \% \mathrm{CI}=0.47-0.83)$, but not in men $(\mathrm{OR}=0.86 ; 95 \% \mathrm{CI}=0.58-1.13)$.

In the dose-response analysis, we found a $4 \%$ decreased risk of biliary tract cancer $(R R=0.96,95 \%$ $\mathrm{CI}=0.93-0.98, p=0.001)$ with each additional cup/ day. Furthermore, when we stratified the dose-response analysis by type of cancer, we found the risks of GB cancer and EXHBDC decreased by $4 \%$ and $5 \%$, respectively.

An important ingredient of tea is tea polyphenols, which are an important type of antioxidant. Tea polyphenols, also known as catechins, have four important types of component, namely (-)-epigallocatechin gallate (EGCG), (-)-epigallocatechin (EGC), (-)-epicatechin gallate (ECG), and (-)-epicatechin (EC) [36]. EGCG is the main tea catechins and also plays the most important role in inhibiting the formation of cancer [37]. Firstly, it can suppress the growth of cancer cells and induce their apoptosis [38]. Moreover, it can suppress receptordependent signaling pathways and angiogenesis, thus preventing tumorigenesis [39]. Secondly, a common characteristic of tumor cells is methylation of DNA, which plays an important role in epigenetic mechanisms for silencing various genes. EGCG contained in the tea polyphenols can inhibit this biochemical process, thus preventing or reversing related gene-silencing in cancer cells [40]. Thirdly, tea polyphenols can inhibit activities of enzyme, including DNA methyltransferase, dihydrofolate reductase, glucose-6-phosphate dehydrogenase, and glyceraldehyde-3-phosphate dehydrogenase, thus preventing cancer formation [41]. Although many studies have suggested that tea can prevent cancer formation and have elucidated the mechanism, the mechanism about tea and biliary tract cancer is still unclear.

Our study has several strengths. First, it is the first to explore the dose-response relationship between tea intake and the risk of biliary tract cancer. Second, we performed
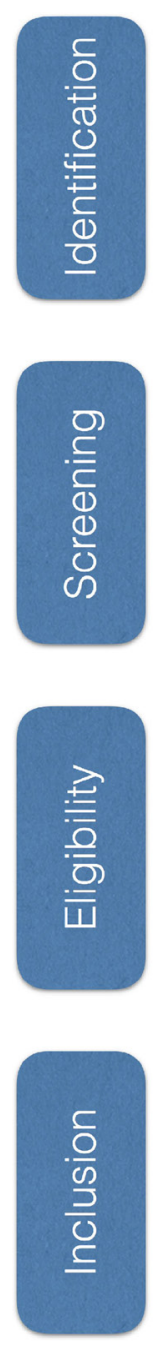

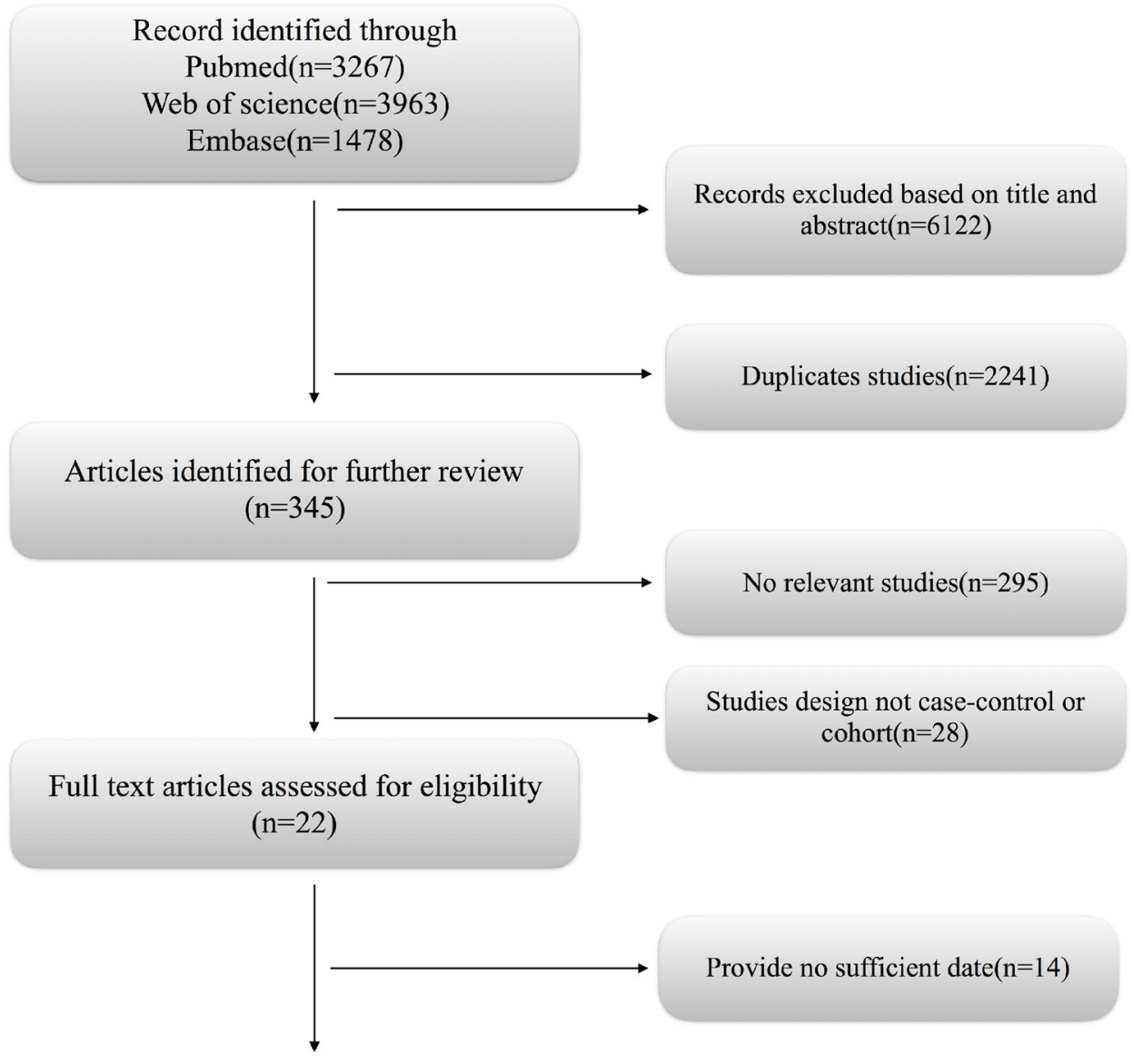

Studies included in final analysis prospective cohort studies $(\mathrm{n}=3)$ case control studies $(\mathrm{n}=5)$

Figure 1: The process of selecting studies for the meta-analysis. 
subgroup and sensitivity analyses to determine the factors affecting the risks. Third, most of the studies included in our meta-analysis were of high quality. All of these characteristics make the conclusions of our study more convincing.

However, there are still several limitations that must be taken into account. First, there are many type of teas, including green, black, and oolong tea [42]. However, we were unable to retrieve information about the type of teas, which might have influenced the virtual results. For example, researcher has reported that green tea reduces cancer risk more strongly than black tea [43]. Secondly, the heterogenicity among studies was obvious and acted as another potential limitation of this study. Third, although we did address a number of adjustment factors, we could not address all potential adjustment factors. People with biliary cancer may stop drinking caffeine-containing beverage and pay more attention on physical exercise, which might have influenced the impact on risk. Finally, our study comprised five case control and only three cohort studies. The former was prone to generate recall and selection biases.

In summary, we found that tea is associated with a $34 \%$ lower incidence of biliary tract cancer. Subgroup analysis showed that tea consumption is associated with decreased risk of GB and EXHBDC with $28 \%$ and $20 \%$, respectively. However, more prospective studies and basic research are still urgently needed to further validate the association between tea and biliary cancer and the potential mechanisms.

\section{MATERIALS AND METHODS}

\section{Data sources and search strategy}

We searched published reports in the PubMed, EMBASE and Web of Science using the following keywords: ("tea OR beverages OR diet OR drinking OR risk factor") and ("gallbladder cancer" OR "gallbladder carcinoma" OR "gallbladder tumor" OR "gallbladder neoplasms" OR "biliary tract cancer" OR "bile duct cancer" OR "cholangiocarcinoma"). We placed no restrictions on the language or date of publication.

\section{Eligibility criteria for study selection}

The eligibility criteria were as follows: study design (case control or cohort); exposure factor tea and outcome biliary tract cancer, including cancers of the GB, EXHBD, and VOA; and odds ratio (OR)/risk ratio (RR) values and corresponding $95 \%$ confidence intervals (CIs) for different categories of tea consumption available or sufficient information provided to enable the calculation

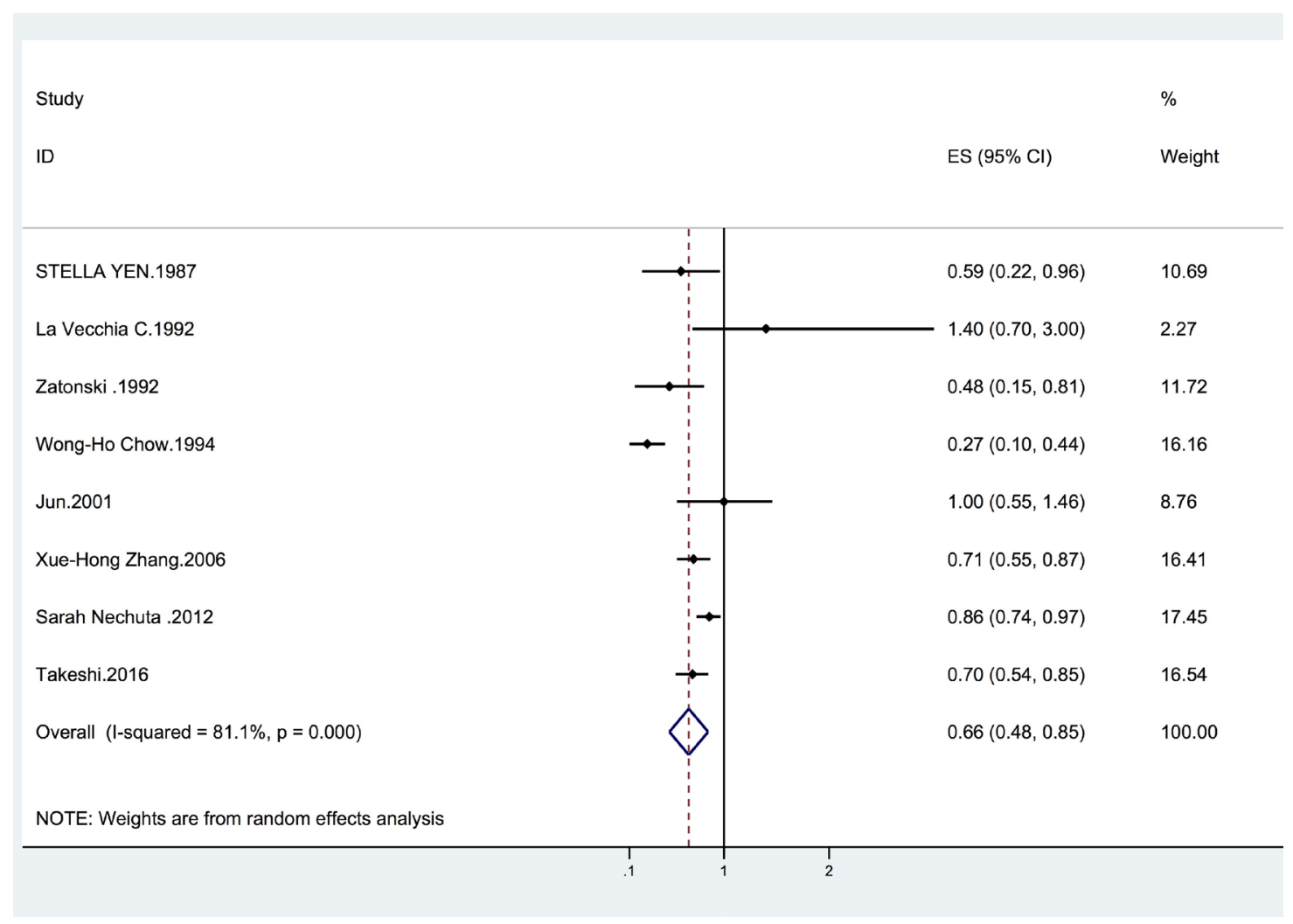

Figure 2: Forrest plot showing the relationship between tea and the risk of biliary tract cancer. Points represent the risk estimate for each individual study. horizontal lines represent $95 \%$ confidence interval; diamonds represent the summary risk estimate with $95 \%$ confidence interval. CI, confidence interval. ES, effect size. 
Table 1: Subgroup analyses for tea consumption on risk of biliary tract cancer

\begin{tabular}{|c|c|c|c|c|}
\hline Subgroup & No. of studies & RR (95\% CI) & $I^{2}$ value $(\%)$ & $P$ value \\
\hline All studies & 8 & $0.66(0.48,0.85)$ & 81.1 & 0.001 \\
\hline \multicolumn{5}{|l|}{ Subtype of cancer } \\
\hline GC & 6 & $0.72(0.56,0.88)$ & 56.1 & 0.044 \\
\hline EXHBDC & 5 & $0.80(0.71,0.89)$ & 0.3 & 0.404 \\
\hline VOA & 4 & $0.78(0.49,1.08)$ & 59.8 & 0.083 \\
\hline \multicolumn{5}{|l|}{ Study design } \\
\hline case-control & 5 & $0.62(0.44,0.80)$ & 55.8 & 0.009 \\
\hline cohort & 3 & $0.84(0.77,0.90)$ & 0.6 & 0.001 \\
\hline \multicolumn{5}{|l|}{ Gender } \\
\hline male & 2 & $0.86(0.58,1.13)$ & 0 & 0.650 \\
\hline female & 3 & $0.65(0.47,0.83)$ & 86.7 & 0.001 \\
\hline male and female & 5 & $0.72(0.57,0.87)$ & 24.0 & 0.246 \\
\hline \multicolumn{5}{|l|}{ Geographic areas } \\
\hline West & 4 & $0.45(0.24,0.65)$ & 36.2 & 0.152 \\
\hline East & 4 & $0.81(0.74,0.88)$ & 21.4 & 0.001 \\
\hline \multicolumn{5}{|l|}{ No. of case } \\
\hline$\geq 200$ & 3 & $0.79(0.70,0.88)$ & 48.9 & 0.081 \\
\hline$<200$ & 5 & $0.68(0.47,0.88)$ & 61.9 & 0.002 \\
\hline \multicolumn{5}{|l|}{ Publication time } \\
\hline$\geq 2000$ & 4 & $0.81(0.74,0.88)$ & 21.4 & 0.240 \\
\hline$<2000$ & 4 & $0.45(0.24,0.65)$ & 36.2 & 0.152 \\
\hline \multicolumn{5}{|c|}{ Duration of fallow-up } \\
\hline$\geq 5$ & 2 & $0.83(0.76,0.90)$ & 11.6 & 0.340 \\
\hline$<5$ & 6 & $0.65(0.47,0.83)$ & 58.5 & 0.004 \\
\hline \multicolumn{5}{|l|}{ Study quality } \\
\hline$\geq 7$ & 6 & $0.80(0.73,0.88)$ & 25.7 & 0.207 \\
\hline$<7$ & 2 & $0.55(0.31,0.80)$ & 56.5 & 0.024 \\
\hline \multirow{2}{*}{\multicolumn{5}{|c|}{$\begin{array}{l}\text { Adjustment for confounders } \\
\text { cholelithiasis }\end{array}$}} \\
\hline & & & & \\
\hline Yes & 2 & $0.70(0.54,0.85)$ & 0 & 0.367 \\
\hline No & 6 & $0.71(0.58,0.85)$ & 72.4 & 0.001 \\
\hline \multicolumn{5}{|l|}{ smoking } \\
\hline Yes & 4 & $0.62(0.38,0.87)$ & 70.3 & 0.001 \\
\hline No & 4 & $0.79(0.70,0.88)$ & 37.2 & 0.111 \\
\hline \multicolumn{5}{|l|}{ Body Mass Index } \\
\hline Yes & 3 & $0.84(0.77,0.90)$ & 0.6 & 0.412 \\
\hline No & 5 & $0.62(0.44,0.80)$ & 55.8 & 0.009 \\
\hline \multicolumn{5}{|l|}{ Eduction } \\
\hline Yes & 5 & $0.81(0.73,0.90)$ & 30.3 & 0.158 \\
\hline No & 3 & $0.54(0.32,0.75)$ & 69.5 & 0.008 \\
\hline
\end{tabular}

$\mathrm{RR}$, relative risk; CI, confidence interval. 
A

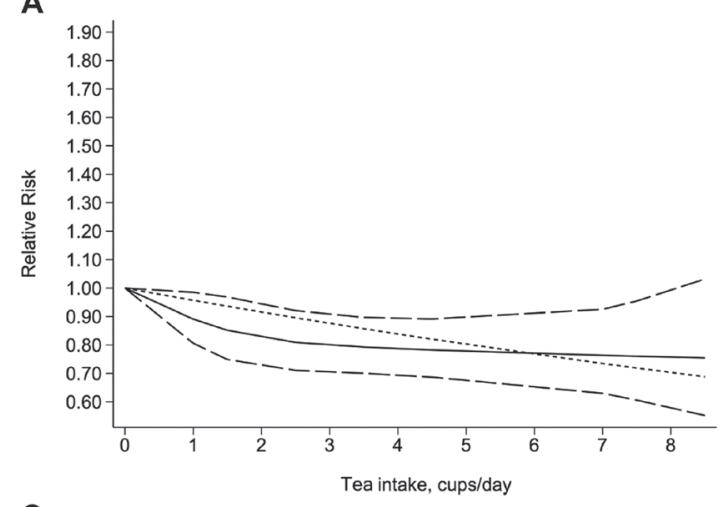

C

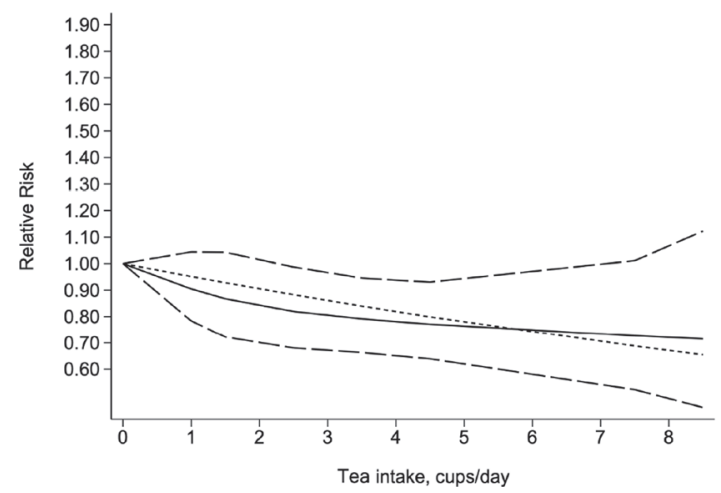

B

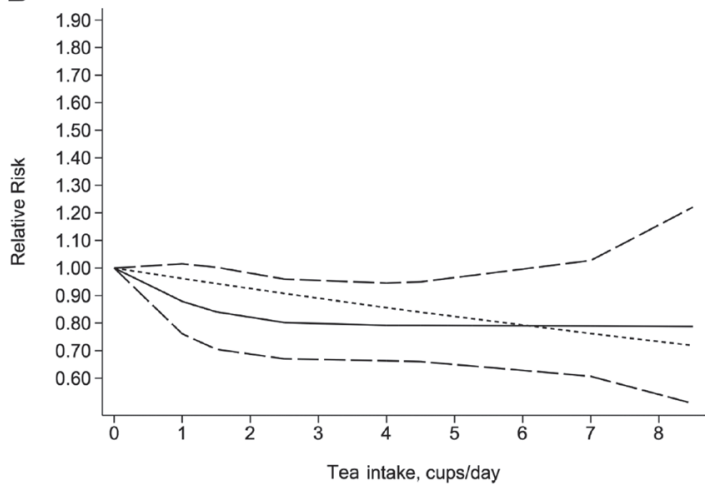

Figure 3: Dose-response relationship between tea intake and the risk of biliary tract cancer (A), gallbladder cancer (B), extra hepatic bile ducts cancer $(\mathbf{C})$. The solid line and the long dash line represent the estimated relative risks and its 95\% confidence interval. Short dash line represents the linear relationship.

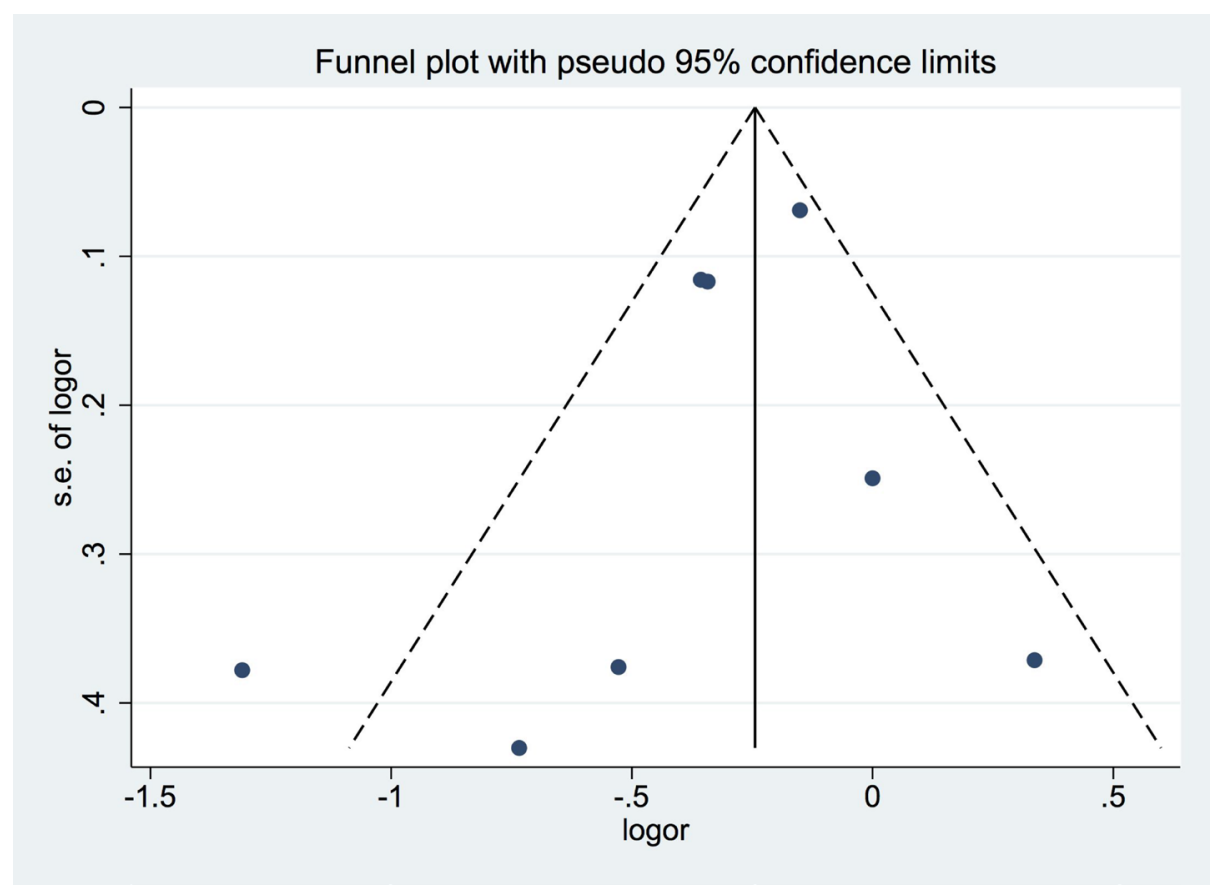

Figure 4: Funnel plot for studies included in the meta-analysis of the relationship between tea intake and biliary tract cancer risk. LogOR: Log odds ratio. SE: standard error. 
of these variables. If two studies reported the same data, we selected the study with the larger sample.

\section{Data abstraction and quality assessment}

Two researchers independently extracted the required information from the selected reports in a standardized manner. We collected the following information from each article: year of publication, first author's name and country of origin, study design (case control or cohort), number of participants (cases, controls, or cohort size), duration of follow-up, types of cancer, sex of participants, sources of controls, comparison of exposure levels, potential adjusted confounding variables, OR/RR values and $95 \%$ CIs for different categories of tea consumption, and quality score. To assess the doseresponse, we also collected the number of case and personyears for each category of tea consumption.

We used the Newcastle- Ottawa Scale (NOS) [44] to evaluate the quality of included studies. We assigned quality categories based on the scores of each study. The categories were the following: high quality (score 7-9), medium quality (score 4-6) and low quality (score less than 4) [45]. We resolved discrepancies by consensus.

\section{Statistical analyses}

We assessed the relationship between tea consumption and biliary tract cancer using OR/RR values and the corresponding 95\% CIs. When the results provided were for multiple groups of tea consumption with OR or RR values and corresponding 95\% confidence intervals, we combined them to obtain a single $\mathrm{OR} / \mathrm{RR}$ value and corresponding $95 \%$ CI [45]. We treated the hazard ratio as equivalent to the RR. When separate results were reported for men and women, we analyzed the findings for men and women as two different independent reports. Additionally, when results for subtypes of biliary tract cancers, such as GB cancer, EXHBDC, and VOA, were reported, we analyzed data for each subtype of cancer as an independent report.

To enable the meta-analysis of the dose-response, we extracted the number of cases and person-years and RRs with variance estimates for at least three quantitative exposure categories from each study. If the studies did not provide these data, we required sufficient information to calculate them. If the intake of tea was reported as amount per year or lifetime, we calculated the daily intake. If studies did not provide tea intake in terms of cups, we assumed $120 \mathrm{~mL}$ or $50 \mathrm{~g}$ as one cup [31, 35]. For dose-response analysis, we used the midpoint of tea intake in each category as the dose of tea consumed. If the highest category was open- ended, we set the midpoint of the category at 1.5 times the lower boundary; if the lowest category was open-ended, we set the lowest boundary at zero [46]. Additionally, we used restricted cubic splines with four knots at fixed percentiles $(5 \%$, $35 \%, 65 \%$, and $95 \%$ ) of the distribution to evaluate a potential linear relationship between tea consumption and the risk of biliary tract cancer. A $p$ value for the curve linearity relationship was calculated by testing whether the coefficient of the second spline was zero [47]. Greenland and Orsini were the pioneers of this method [48, 49] [50], we use the method to test a simple quadratic term to the linear model and it was based on the results across categories of tea consumption. Many subsequent studies have described it in detail $[51,52]$.

We used $\mathrm{I}^{2}$ to assess heterogeneity between studies and defined low, medium, and high heterogeneity as $25 \%$, $50 \%$, and $75 \%$, respectively [53]. If p was less than 0.1 , we assumed definite heterogeneity. We used the fixed effect model when the heterogeneity was not substantial and the random effects model when there was a significant heterogeneity [54]. We evaluated publication bias by funnel plots, with funnel plot asymmetry indicating the presence of bias [55].

We also performed subgroup analyses by subtype of cancer, study design, sex, geographic area, number of cases, date of publication, duration of follow-up, study quality (NOS scores), and whether cholelithiasis, smoking, body mass index or education was adjusted for in the models. Sensitivity analyses were also performed by excluding studies not eligible for dose-response analysis.

All statistical analyses were performed using STATA version 12.0 (Stata).

\section{Abbreviations}

GC: gallbladder cancer, EXHBDC: extra hepatic bile ducts cancer, VOA: ampulla of Vater cancer.

\section{Authors' contributions}

J.X. designed the study and wrote this manuscript. J.L. and A.W. searched database and reviewed studies. Y.W., Y.X., X.S. collected and analyzed data. X.L. and H.Z. coordinated and provided financial support for this work. All of the authors have read and approved the final manuscript.

\section{CONFLICTS OF INTEREST}

None.

\section{FUNDING}

This work was supported by International Science and Technology Cooperation Projects (2015DFA30650 and 2016YFE0107100), The Capital Special Research Project for the clinical application (Z151100004015170), Capital Special Research Project for Health Development 
(2014-2-4012), Beijing Nature Science Foundation for Young Scholars Project (7164293), Program for New Century Excellent Talents in University (NCET-11-0288).

\section{REFERENCES}

1. de Groen PC, Gores GJ, LaRusso NF, Gunderson LL, Nagorney DM. Biliary Tract Cancers. New England Journal of Medicine. 1999; 341:1368-1378.

2. Lepage C, Cottet V, Chauvenet M, Phelip JM, Bedenne L, Faivre J, Bouvier AM. Trends in the incidence and management of biliary tract cancer: A French populationbased study. Journal of Hepatology. 2011; 54:306-310.

3. Randi G, Malvezzi M, Levi F, Ferlay J, Negri E, Franceschi S, La Vecchia C. Epidemiology of biliary tract cancers: an update. Annals of Oncology. 2009; 20:146-159.

4. Landis SH, Murray T, Bolden S, Wingo PA. Cancer statistics, 1998. CA Cancer J Clin. 1998; 48:6-29.

5. Diehl AK. Gallstone size and the risk of gallbladder cancer. Jama. 1983; 250:2323-2326.

6. Flood TA, Jain D, Marginean EC. Malignant tumours of gallbladder and extrahepatic bile ducts. Diagnostic Histopathology. 2010; 16:360-370.

7. Lowenfels $\mathrm{AB}$, Maisonneuve $\mathrm{P}$, Boyle P, Zatonski WA. Epidemiology of gallbladder cancer. Hepato-Gastroenterology. 1999; 46:1529-1532.

8. Karlsen TH, Schrumpf E, Boberg KM. Primary sclerosing cholangitis. Best Practice \& Research in Clinical Gastroenterology. 2010; 24:655-666.

9. Nordenstedt H, Mattsson F, El-Serag H, Lagergren J. Gallstones and cholecystectomy in relation to risk of intra- and extrahepatic cholangiocarcinoma. British Journal of Cancer. 2012; 106:1011-1015.

10. Kilander C, Mattsson F, Lu Y, Ljung R, Lagergren J, SadrAzodi O. Reproductive factors and risk of biliary tract cancer in a population-based study. Acta Oncologica. 2015; 54:1152-1158.

11. Schlesinger S, Aleksandrova K, Pischon T, Jenab $M$, Fedirko V, Trepo E, Overvad K, Roswall N, Tjonneland A, Boutron-Ruault MC, Fagherazzi G, Racine A, Kaaks R, et al. Diabetes mellitus, insulin treatment, diabetes duration, and risk of biliary tract cancer and hepatocellular carcinoma in a European cohort. Annals of Oncology. 2013; 24:2449-2455.

12. Wang F, Wang BY, Qiao L. Association between obesity and gallbladder cancer. Frontiers in Bioscience-Landmark. 2012; 17:2550-2558.

13. Chow WH, McLaughlin JK, Hrubec Z, Fraumeni JF. Smoking and biliary tract cancers in a cohort of US veterans. Br J Cancer. 1995; 72:1556-1558.

14. Rosato V, Bosetti C, Dal Maso L, Montella M, Serraino D, Negri E, La Vecchia C. Medical conditions, family history of cancer, and the risk of biliary tract cancers. Tumori. 2016; 102:252-257.
15. Muraki S, Yamamoto S, Ishibashi H, Horiuchi T, Hosoi T, Suzuki T, Orimo H, Nakamura K. Green tea drinking is associated with increased bone mineral density. Journal of Bone and Mineral Research. 2003; 18:S241-S241.

16. Sesso HD, Gaziano JM, Buring JE, Hennekens CH. Coffee and tea intake and the risk of myocardial infarction. American Journal of Epidemiology. 1999; 149:162-167.

17. Arts ICW. A review of the epidemiological evidence on tea, flavonoids, and lung cancer. Journal of Nutrition. 2008; 138:1561-1566.

18. Boggs DA, Palmer JR, Stampfer MJ, Spiegelman D, AdamsCampbell LL, Rosenberg L. Tea and coffee intake in relation to risk of breast cancer in the Black Women's Health Study. Cancer Causes \& Control. 2010; 21:1941-1948.

19. Hartman TJ, Tangrea JA, Pietinen P, Malila N, Virtanen M, Taylor PR, Albanes D. Tea and coffee consumption and risk of colon and rectal cancer in middle-aged Finnish men. Nutrition and Cancer. 1998; 31:41-48.

20. Hoshiyama Y, Kawaguchi T, Miura Y, Mizoue T, Tokui N, Yatsuya H, Sakata K, Kondo T, Kikuchi S, Toyoshima H, Hayakawa N, Tamakoshi A, Ohno Y, et al. A prospective study of stomach cancer death in relation to green tea consumption in Japan. British Journal of Cancer. 2002; 87:309-313.

21. Sang LX, Chang B, Li XH, Jiang M. Green Tea Consumption and Risk of Esophageal Cancer: A MetaAnalysis of Published Epidemiological Studies. Nutrition and Cancer. 2013; 65:802-812.

22. Ide R, Fujino $\mathrm{Y}$, Hoshiyama $\mathrm{Y}$, Mizoue $\mathrm{T}$, Kubo T, Pham TM, Shirane K, Tokui N, Sakata K, Tamakoshi A, Yoshimura T, JACC Study Group. A prospective study of green tea consumption and oral cancer incidence in Japan. Annals of Epidemiology. 2007; 17:821-826.

23. Li Q, Kakizaki M, Kuriyama S, Sone T, Yan H, Nakaya N, Mastuda-Ohmori K, Tsuji I. Green tea consumption and lung cancer risk: the Ohsaki study. British Journal of Cancer. 2008; 99:1179-1184.

24. Myung SK, Bae WK, Oh SM, Kim Y, Ju W, Sung J, Lee YJ, Ko JA, Song JI, Choi HJ. Green tea consumption and risk of stomach cancer: A meta-analysis of epidemiologic studies. International Journal of Cancer. 2009; 124:670-677.

25. Pathy NB, Peeters P, van Gils C, Beulens JWJ, van der Graaf Y, Bueno-de-Mesquita B, Bulgiba A, Uiterwaal CSPM. Coffee and tea intake and risk of breast cancer. Breast Cancer Research and Treatment. 2010; 121:461-467.

26. Qin J, Xie B, Mao Q, Kong D, Lin Y, Zheng X. Tea consumption and risk of bladder cancer: a meta-analysis. World journal of surgical oncology. 2012; 10.

27. Huang YQ, Lu X, Min H, Wu QQ, Shi XT, Bian KQ, Zou XP. Green tea and liver cancer risk: A meta-analysis of prospective cohort studies in Asian populations. Nutrition. $2016 ; 32: 3-8$.

28. La Vecchia C, Negri E, Franceschi S, D’Avanzo B, Boyle P. Tea consumption and cancer risk. Nutrition and cancer. $1992 ; 17: 27-31$. 
29. Nagano J, Kono S, Preston DL, Mabuchi K. A prospective study of green tea consumption and cancer incidence, Hiroshima and Nagasaki (Japan). Cancer causes \& control. 2001; 12:501-508.

30. Zatonski WA, La Vecchia C, Przewozniak K, Maisonneuve P, Lowenfels AB, Boyle P. Risk factors for gallbladder cancer: a Polish case-control study. Int J Cancer. 1992; 51:707-711.

31. Nechuta S, Shu XO, Li HL, Yang G, Ji BT, Xiang YB, Cai H, Chow WH, Gao YT, Zheng W. Prospective cohort study of tea consumption and risk of digestive system cancers: results from the Shanghai Women's Health Study. The American journal of clinical nutrition. 2012; 96:1056-1063.

32. Chow WH, McLaughlin JK, Menck HR, Mack TM. Risk factors for extrahepatic bile duct cancers: Los Angeles County, California (USA). Cancer causes \& control. 1994; 5:267-272.

33. Yen S, Hsieh CC, MacMahon B. Extrahepatic bile duct cancer and smoking, beverage consumption, past medical history, and oral-contraceptive use. Cancer. 1987; 59:2112-2116.

34. Zhang XH, Andreotti G, Gao YT, Deng J, Liu E, Rashid A, Wu K, Sun L, Sakoda LC, Cheng JR, Shen MC, Wang BS, Han TQ, et al. Tea drinking and the risk of biliary tract cancers and biliary stones: a population-based case-control study in Shanghai, China. Int J Cancer. 2006; 118:3089-3094.

35. Makiuchi T, Sobue T, Kitamura T, Ishihara J, Sawada N, Iwasaki M, Sasazuki S, Yamaji T, Shimazu T, Tsugane S. Association between green tea/coffee consumption and biliary tract cancer: A population-based cohort study in Japan. Cancer Science. 2016; 107:76-83.

36. Yang CS, Maliakal P, Meng XF. Inhibition of carcinogenesis by tea. Annual Review of Pharmacology and Toxicology. 2002; 42:25-54.

37. $\mathrm{Ju} \mathrm{J}, \mathrm{Lu} \mathrm{G}$, Lambert JD, Yang CS. Inhibition of carcinogenesis by tea constituents. Seminars in Cancer Biology. 2007; 17:395-402.

38. Yang GY, Liao J, Kim K, Yurkow EJ, Yang CS. Inhibition of growth and induction of apoptosis in human cancer cell lines by tea polyphenols. Carcinogenesis. 1998; 19:611-616.

39. Shimizu M, Deguchi A, Lim JTE, Moriwaki H, Kopelovich L, Weinstein IB. (-)-epigallocatechin gallate and polyphenon $\mathrm{E}$ inhibit growth and activation of the epidermal growth factor receptor and human epidermal growth factor receptor-2 signaling pathways in human colon cancer cells. Clin Cancer Res. 2005; 11:2735-2746.

40. Fang MZ, Wang YM, Ai N, Hou Z, Sun Y, Lu H, Welsh W, Yang CS. Tea polyphenol (-)-epigallocatechin3-gallate inhibits DNA methyltransferase and reactivates methylation-silenced genes in cancer cell lines. Cancer Res. 2003; 63:7563-7570.

41. Yang CS, Wang X, Lu G, Picinich SC. Cancer prevention by tea: animal studies, molecular mechanisms and human relevance. Nature reviews Cancer. 2009; 9:429-439.
42. Kuroda Y, Hara Y. Antimutagenic and anticarcinogenic activity of tea polyphenols. Mutation Research. 1999; 436:69-97.

43. Wang ZY, Huang MT, Lou YR, Xie JG, Reuhl KR, Newmark HL, Ho CT, Yang CS, Conney AH. Inhibitory effects of black tea, green tea, decaffeinated black tea, and decaffeinated green tea on ultraviolet B light-induced skin carcinogenesis in 7,12-dimethylbenz[a] anthracene-initiated SKH-1 mice. Cancer Res. 1994; 54:3428-3435.

44. Stang A. Critical evaluation of the Newcastle-Ottawa scale for the assessment of the quality of nonrandomized studies in meta-analyses. European Journal of Epidemiology. 2010; 25:603-605.

45. Zhang YP, Li WQ, Sun YL, Zhu RT, Wang WJ. Systematic review with meta-analysis: coffee consumption and the risk of gallstone disease. Alimentary pharmacology \& therapeutics. 2015; 42:637-648.

46. Rong Y, Chen L, Zhu T, Song Y, Yu M, Shan Z, Sands A, $\mathrm{Hu}$ FB, Liu L. Egg consumption and risk of coronary heart disease and stroke: dose-response meta-analysis of prospective cohort studies. BMJ. 2013; 346:e8539.

47. Desquilbet L, Mariotti F. Dose-response analyses using restricted cubic spline functions in public health research. Stat Med. 2010; 29:1037-1057.

48. Orsini N, Li R, Wolk A, Khudyakov P, Spiegelman D. Metaanalysis for linear and nonlinear dose-response relations: examples, an evaluation of approximations, and software. Am J Epidemiol. 2012; 175:66-73.

49. Orsini N, Bellocco R, Greenland S. Generalized least squares for trend estimation of summarized dose-response data. Stata Journal. 2006; 6:40-57.

50. Greenland S, Longnecker MP. Methods for trend estimation from summarized dose-response data, with applications to meta-analysis. Am J Epidemiol. 1992; 135:1301-1309.

51. Wang AQ, Wang SS, Zhu CP, Huang HC, Wu LC, Wan XS, Yang XB, Zhang HH, Miao RY, He L, Sang XT, Zhao HT. Coffee and cancer risk: A meta-analysis of prospective observational studies. Scientific Reports. 2016; 6.

52. Guo P, Xu C, Zhou Q, Zhou J, Zhao J, Si Z, Shen C, Feng C. Number of parity and the risk of gallbladder cancer: a systematic review and dose-response metaanalysis of observational studies. Arch Gynecol Obstet. 2016; 293:1087-1096.

53. Higgins JPT, Thompson SG. Quantifying heterogeneity in a meta-analysis. Statistics in Medicine. 2002; 21:1539-1558.

54. Dersimonian R, Laird N. Meta-analysis in clinical trials. Controlled Clinical Trials. 1986; 7:177-188.

55. Stuck AE, Rubenstein LZ, Wieland D. Bias in meta-analysis detected by a simple, graphical test - Asymmetry detected in funnel plot was probably due to true heterogeneity. Br Med J. 1998; 316:469. 